\title{
Bridging the Gap between Brain-Derived Neurotrophic Factor and Glucocorticoid Effects on Brain Networks
}

\author{
Freddy Jeanneteau ${ }^{a} \quad$ Amélie Borie $^{a}$ Moses V. Chao ${ }^{b}$ Michael J. Garabedianc \\ ${ }^{a}$ Institut de Genomique Fonctionnelle, Inserm, CNRS, University of Montpellier, Montpellier, France; \\ ${ }^{b}$ Skirball Institute of Biomolecular Medicine, New York University Langone Medical Center, New York, NY, USA; \\ 'New York University Langone Medical Center, New York, NY, USA
}

\section{Keywords}

Stress - Connectivity · Salience network - Action control ·

Depression

\begin{abstract}
Behavioral choices made by the brain during stress depend on glucocorticoid and brain-derived neurotrophic factor (BDNF) signaling pathways acting in synchrony in the mesolimbic (reward) and corticolimbic (emotion) neural networks. Deregulated expression of BDNF and glucocorticoid receptors in brain valuation areas may compromise the integration of signals. Glucocorticoid receptor phosphorylation upon BDNF signaling in neurons represents one mechanism underlying the integration of BDNF and glucocorticoid signals that when off balance may lay the foundation of maladaptations to stress. Here, we propose that BDNF signaling conditions glucocorticoid responses impacting neural plasticity in the mesocorticolimbic system. This provides a novel molecular framework for understanding how brain networks use BDNF and glucocorticoid signaling contingencies to forge receptive neuronal fields in temporal domains defined by behavioral experience, and in mood disorders.
\end{abstract}

(c) 2018 S. Karger AG, Basel

\section{KARGER}

(C) 2018 S. Karger AG, Basel

E-Mail karger@karger.com

www.karger.com/nen

\section{Introduction}

Stress coping is paramount for survival in most species including humans [1]. The neuro-endocrine stress response interacts with neuronal circuitry to select suitable behavioral strategies based on outcomes [2, 3]. Processing of information in the face of ongoing and future behavioral demands is crucial for maintaining health $[4,5]$. Therefore, it is essential that during stress the appropriate molecular mechanisms be engaged to promote vigilance, learning, and adaptation $[6,7]$. What happens when this selection of actions goes awry? Cognitive distortions may result when the integration of positive and negative events is devalued [8]. Therefore, it is important to understand how the brain neural circuitry confronts the values of upcoming and previous actions [9]. Growing evidence indicates that abnormal feedback sensitivity between various corticostriatal loops and the reward system could be associated with the occurrence of depressive episodes [8].

In this mini-review, we briefly describe the contributions of the mesolimbic dopaminergic and corticolimbic glutamatergic systems to the stress response. We describe the molecular mediators, signaling pathways, and neuroanatomic feature that foster the adaptive and maladaptive response to stress. We also apply these concepts to how individuals respond and discuss clinical implications.

Freddy Jeanneteau

Institut de Genomique Fonctionnelle, Inserm, CNRS

University of Montpellier

FR-34090 Montpellier (France)

E-Mail freddy.jeanneteau @igf.cnrs.fr 


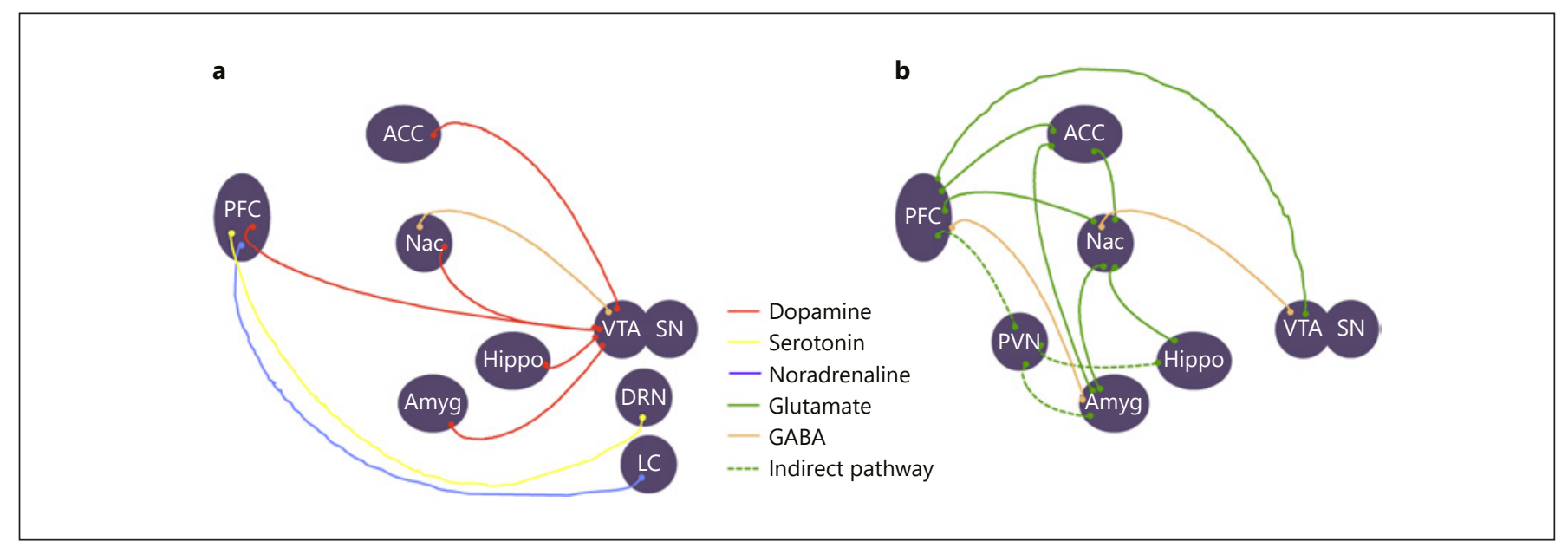

Fig. 1. Schematic representation of the mesolimbic (a) and corticolimbic (b) networks. The core VTA-Nac-PFC dopaminergic pathway processes rewarding functions. The dopaminoceptive neocortical regions reciprocally project glutamatergic neurons to the Nac and VTA to control emotions and to the hypothalamus and amygdala to prepare for novelty via stress-controlled hypotha- lamic neurons. VTA, ventral tegmental area; SN, substantia nigra; DRN, dorsal raphe nucleus; LC, locus coeruleus; Hippo, hippocampus; Amyg, amygdala; PVN, hypothalamic paraventricular nucleus; Nac, nucleus accumbens; ACC, anterior cingulate cortex; PFC, prefrontal cortex.

\section{Cooperation between the Mesolimbic and Corticolimbic Systems Determines Behavioral Choices}

The mesocorticolimbic system plays important roles in emotional and cognitive functions of the human and rodent brains. Disturbances in this system are associated with drug abuses, depression, and autism $[10,11]$. While the mesolimbic system is involved in reward processes, the corticolimbic system mediates attention and cognitive processes. Both systems are interconnected at the ventral tegmental area (VTA), neocortical areas (e.g., PFC, hippocampus), and subcortical limbic areas, including the nucleus accumbens (Nac) and the basolateral amygdala (Fig. 1). The Nac serves as the interface between the limbic and motor regions to bring about motivation and selection of behavioral actions based on incentive stimuli [3]. Beyond this core of motivationally salient neuronal network, additional regions like the insula, the orbitofrontal cortex, the septum, the extended amygdala, and the hypothalamus code for the differential valence of stimuli (e.g., appetitive or aversive) via circuit-specific neuromodulators (e.g., CRF, catecholamines, vasopressin, oxytocin) and uses this information to select actions based on outcome [12].

The synchrony of mesolimbic and corticolimbic networks permits value-based learning [3]. The mesocorti- colimbic network uses a reward-prediction error system to calculate the costs versus benefits of future actions based on their consequences [13]. The uncertainty associated with the novelty and unpredictability of a situation produces correlated activities of the anterior cingulate cortex and the amygdala, which projects to: (i) the locus coeruleus to control vigilance via the noradrenaline pathway, and (ii) the hypothalamus to control the cost of actions through the hypothalamic-pituitary-adrenal (HPA) and glucocorticoid axes [2]. The stress response has an adaptive function through glucocorticoids that is complementary to the reward-prediction error response of the mesocorticolimbic system as it facilitates vigilance, learning, and adaptation [14]. Noradrenaline increases neurotransmission of a "vigilant state" at cortical and amygdala synapses, which glucocorticoids can tune by modifying synaptic plasticity (e.g., LTP, LTD) to trigger adaptation. Glucocorticoids can also promote learning by facilitating new synapse formation and maintenance in the face of behavioral demands [15-18]. It is noteworthy that stress employs predictive coding through the interplay of mesolimbic and corticolimbic systems to reduce the uncertainty about selection of actions based on consequences. 
a

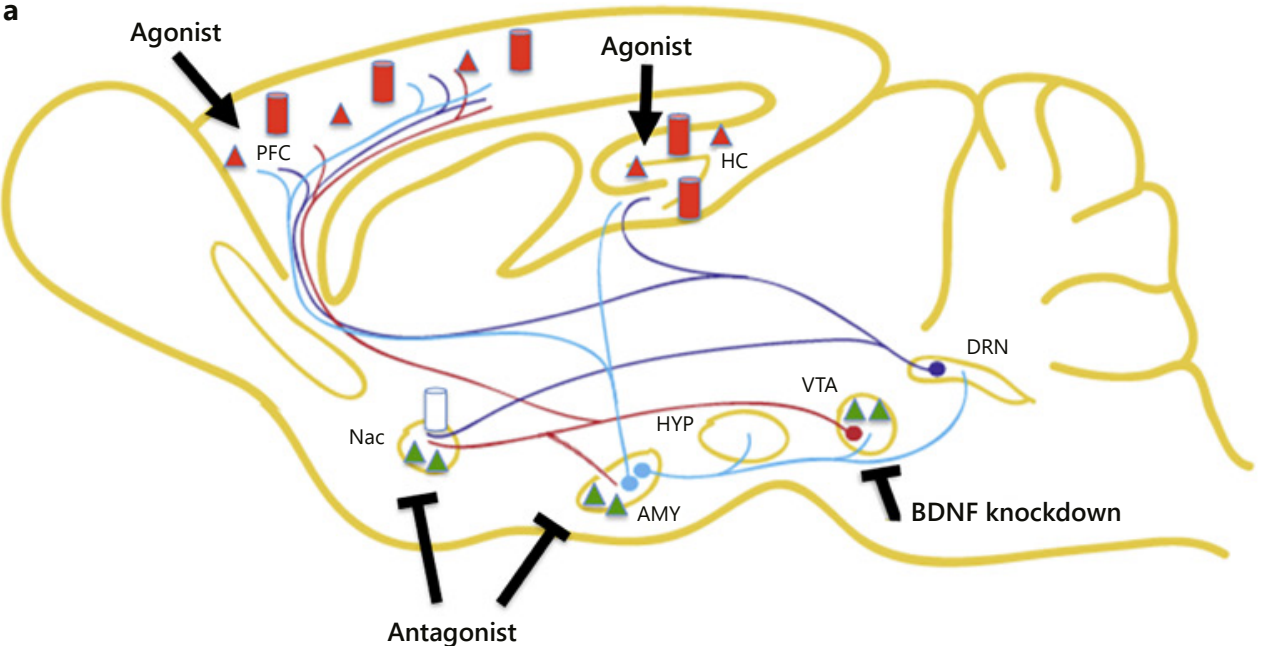

BDNF increase
$\Delta$ BDNF decrease
BDNF no change
TrkB increase
TrkB decrease
TrkB no change
- Serotoninergic projection
- Dopaminergic projection
- Glutamatergic projection

b

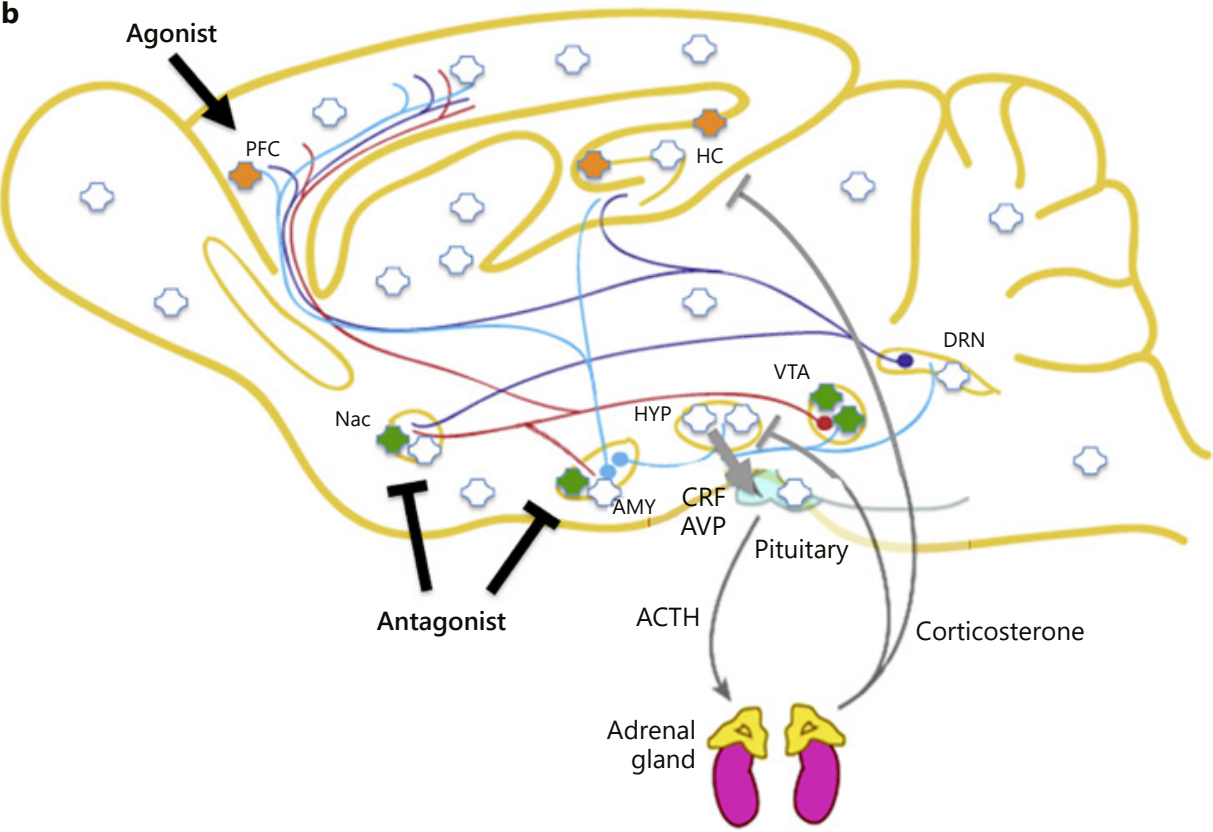

GR increase

GR decrease

GR no change

- Serotoninergic projection

- Dopaminergic projection

- Glutamatergic projection

Fig. 2. Expression of BDNF, TrkB, and GR in mesocorticolimbic areas of the stressed brain [adapted from 30]. a Levels of BDNFTrkB may decrease in brain areas of the corticolimbic pathway but increase in areas of the mesolimbic pathway. TrkB agonists $(7,8$ $\mathrm{DHF}$ ) injected in the prefrontal cortex (PFC) and TrkB antagonists (ANA-12) injected in the Nac can ameliorate the stress-induced depressive phenotype. $\mathbf{b}$ Levels of GR may decrease in brain areas of the corticolimbic pathway but increase in areas of the mesolimbic pathway. GR agonist (corticosterone) injected in PFC and GR antagonists (RU486) injected in Nac or amygdala (AMY) can ameliorate the stress-induced depressive phenotype. GR expression is relatively stable in the adult stressed brain, notably in regions controlling the secretion of ACTH and glucocorticoids in the bloodstream. The HPA axis consists of stress-controlled CRF and AVP hypothalamic neurons that integrate excitatory stimuli from the brainstem and inhibitory signals from cortical/subcortical areas into appropriate ACTH and glucocorticoid responses by the pituitary and adrenal glands, respectively. HC, hippocampus; DRN, dorsal raphe nucleus; HYP, hypothalamus; VTA, ventral tegmental area; ACTH, adrenocorticotropic hormone; CRF, corticotropin-releasing factor; AVP, arginine vasopressin. 


\section{Brain Region-Specific Effects of Brain-Derived Neurotrophic Factor and Glucocorticoids on the Mesocorticolimbic System}

Functional alteration within the circuits of the mesocorticolimbic system or their connectivity could account for changes in behavior. This is influenced by environmental factors, and interactions among areas of the brain during developmental domains as well as in the course of aging. Glucocorticoids and neurotrophins are well-established factors that contribute to the establishment, maintenance, and remodeling of neuronal connections, which can be altered by environmental factors with lasting consequences $[19,20]$. According to the stress hypothesis of depression, the stress-induced glucocorticoid response conditions neuroplasticity mediated by the brain-derived neurotrophic factor (BDNF) [21]. Excessive levels of glucocorticoids or stress suppresses BDNF-mediated neuroplasticity in the corticolimbic pathway, which processes emotional experiences, while it bolsters BDNF-mediated neuroplasticity in the mesolimbic system, which manages reward pathways $[22,23]$. The rationale for this hypothesis relies on epigenetic, transcriptomic, and proteomic regulation of BDNF expression in rodent models and human tissues [24-26]. The consensus view is that expression of BDNF and/or its receptor TrkB is diminished in the corticolimbic system (mostly prefrontal cortex and hippocampus), whereas BDNF is up-regulated in the mesolimbic system (mostly Nac, amygdala, VTA) long after cessation to stressor exposure in animal models and in postmortem human brains [27-31]. A reduction of BDNF/TrkB signaling in the corticolimbic areas of the brain is associated with synaptic loss, decreased neuronal plasticity, and regressing network connectivity, while an elevation of $\mathrm{BDNF} /$ TrkB signaling in the mesolimbic areas of the brain is associated with synaptic growth, increased neuronal plasticity, and expanding network connectivity [32-37]. TrkB agonists in corticolimbic areas and TrkB antagonists in the mesolimbic areas reversed the consequences of chronic stress and depressive-like behaviors (Fig. 2) [28, 38].

Typically, BDNF exerts positive effects on neural plasticity in cortical synapses and in striatal synapses $[39,40]$. In Nac synapses for instance, TrkB activated by VTAderived BDNF, can sensitize reward-seeking behavior and can facilitate social defeat stress [23, 41, 42]. In other words, the BDNF/TrkB signaling can escalate behavioral sensitization to social stress and drug abuse by increasing the plasticity of VTA-Nac synapses. In fact, sensitization of Nac synapses is triggered by stress neuromodulators (e.g., CRF, glucocorticoids) that control secretion and signaling of VTA-derived BDNF [43, 44].

\section{Bridging the Gap between BDNF and Glucocorticoid Effects in the Mesocorticolimbic System}

The difference between mesolimbic and corticolimbic systems seems difficult to explain if considering only the modulation of BDNF by glucocorticoids. Perhaps, cellular reactions to glucocorticoids are also altered by BDNF signaling such that differential responses to TrkB agonists and antagonists in the mesolimbic and corticolimbic systems could be mediated via a glucocorticoid-dependent signaling route. As for the modulations of $\mathrm{BDNF} / \mathrm{TrkB}$, manipulating glucocorticoid receptors (GR) revealed contrasting results between the mesolimbic and corticolimbic pathways. On one hand, GR antagonists impeded stress-induced sensitization of the mesolimbic pathway, but on the other hand GR agonists prevented behavioral vulnerability to stress in corticolimbic areas [45-47]. This reflects decreased GR expression in the prefrontal cortex and hippocampus, and increased GR expression in the amygdala upon stress [48-51]. Epigenetic reprogramming sets the stage for changes in GR expression associated with significant risk of depression and suicide [52, 53]. This is evident in early life trauma where GR expression changes appear to be stable and persist even after stress is alleviated. By contrast, alterations in GR expression in the adult brain upon stress are not stable after the cessation of stress, making it unlikely to be responsible for chronic depression in the adult [54].

What might be responsible for persistent changes in GR responses in the adult brain under chronic stress? It is speculated that alterations of GR activity, rather than its expression, can persist long after chronic stress in the adult brain. Consistently, GR activity is sensitized in the mesolimbic areas of the adult brain while it is desensitized in the corticolimbic areas after stress $[55,56]$. A longlasting loss of GR responsiveness consistent with glucocorticoid resistance in the corticolimbic pathway was monitored in peripheral blood cells of patients with major depressive disorders [57]. When stable overtime, the normalization of GR functions correlates with relief of depressive symptoms after antidepressant therapies [58]. However, relapse is common, associated with a lack of restoration of stable glucocorticoid sensitivity and efficacy $[55,59]$. 
Fig. 3. The GR phosphorylation code. Phosphorylation of the transactivation domain and hinge region $(\mathrm{H})$ at multiple sites conserved interspecies specifies cofactor recruitment for target gene expression. Most sites are dependent on glucocorticoid binding but others respond to BDNF-TrkB signaling [adapted from 63, 86-88].

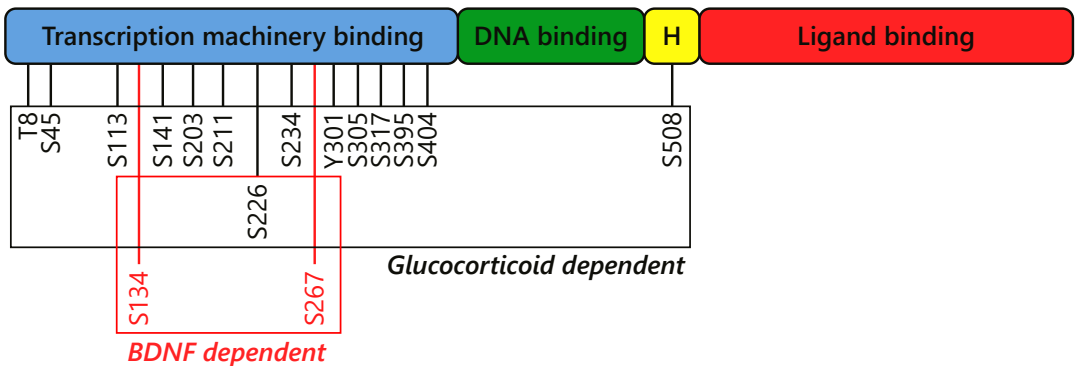

\begin{tabular}{|cccccc|}
\hline Human & Rat & Mouse & Consensus & Kinase & Effector \\
\hline S134 & S155 & S152 & R-S-T-S(p)-V/R-P-E & Erk/JNK & 14-3-3 \\
& & & & P38/AKT1 & PELP1 \\
& & & & CDK5 & CREB1 \\
S203 & S224 & S212 & S(p)-X-R/K & CDK & GRIP1 \\
S211 & S232 & S220 & S(p)-X-R/K & CDK/p38 & GRIP1 \\
S226 & S246 & S234 & non-polar-X-S(p)-P & JNK & GRIP1 \\
S267 & S287 & S284 & L-S-S(p)-P-S-N/S & Erk/JNK & CREB1 \\
\hline
\end{tabular}

\section{GR Phosphorylation Is Influenced by BDNF Signaling}

Given that activation of TrkB responds to antidepressant drugs and that it is required for antidepressant-induced behavioral effects [60], it is possible that BDNF/ TrkB signaling could condition GR responses [20]. Pairing of BDNF and glucocorticoid signaling result in GR phosphorylation in the N-terminal transactivation domain at residues Ser155 and Ser287 (Ser134 and Ser267 in humans) that serve as docking sites for cofactors of signaling [61]. Changes of GR phosphorylation impact GR-mediated transcription and neuronal plasticity. If GR is not phosphorylated on these sites, this results in a distinct GR genomic response and alteration in neuronal plasticity [62]. Thus, it appears that the GR phosphorylation "code" is modified by BDNF signaling (Fig. 3). Such glucocorticoid-independent protein modification provides cell- and signal-specific responses to GR signaling [63]. These findings provide insight into the molecular basis of stress-induced neuroadaptations in the mesocorticolimbic circuitry and perhaps in other tissues. For instance, effects of BDNF signaling on GR are possible not only in the brain, but also in peripheral tissues given that BDNF is present in blood at high levels [64].

\section{Effect of BDNF and Glucocorticoid Signaling in Health and Disease}

Complementary actions of glucocorticoids and BDNF have an important influence on behavior. Both signaling pathways are required to produce actions based on consequences, to form new memories of contextual fear, and to cope with stress [31,65-67]. Given that glucocorticoids can readily access neurons in the brain and BDNF is secreted in an activity-dependent fashion by neuronal networks responding to behavioral experience, it is likely that neuronal networks with ongoing BDNF signaling give rise to a unique GR response via changes in the GR phosphorylation "code" and alterations of the GR genomic response in a cell-type-specific manner [63]. This could explain differential modulation of GR activity in mesolimbic and corticolimbic networks. Deletion of GR phosphorylation sites in neurons belonging to corticolimbic brain areas interferes with the expression of GRregulated target genes involved in cytoskeleton dynamics, mitochondrial functions, synapse formation and maintenance $[62,68,69]$. Furthermore, BDNF-dependent GR phosphorylation sites reside near a caspase- 1 site, whose cleavage causes partial loss of GR transcriptional activity in animal models and a disease of glucocorticoid resistance in humans $[70,71]$. Therefore, BDNF represents a conditioning factor that directs glucocorticoid responses 
through GR phosphorylation in the body, including the mesolimbic and corticolimbic pathways that may lay the foundation for vulnerability or resiliency to stress maladaptations $[60,72]$. This notion is consistent with the theory of general adaptation syndrome whereby a normally well-tolerated degree of stress can become pathogenic if the glucocorticoid response to stressors is inappropriate in the face of conditioning signals (e.g., BDNF, genetic and environmental factors, etc.) [73]. Therefore, deregulation of BDNF expression could compromise GR-directed glucocorticoid responses with consequences on neuronal networks and behaviors. This could explain why some individuals are more vulnerable than others to diseases of adaptation (e.g., mood disorders including depression) despite similar stressful experiences [74, 75]. With this in mind, it is interesting that humans and rodents harboring the BDNF-Met66 genetic variant of the Val66Met polymorphism that suppresses activity-dependent secretion of BDNF, show impaired reactivity to stressors and predisposition to depression [76-78].

Individuals differ in their responses to stress and drug sensitization [79-81]. Whereas resiliency promotes valuebased decision making, stress devalues salient emotional stimuli $[13,14]$. Stress coping styles may differ depending on neuroadaptations in brain regions that mediate actions that control emotional valence (corticolimbic system) and salience (mesolimbic system) [82]. For example, activation of CRF neurons controls BDNF secretion at VTA$\mathrm{Nac}$ synapses in the animals that are vulnerable to social defeat stress [43]. In this paradigm, vulnerability to stress required TrkB at Nac synapses whereas VTA-derived dopamine was dispensable [23]. Stress-induced HPA axis activation is often elevated in those that respond highly to stress, whereas strategies to blunt such HPA hyperactivation could promote resilience $[59,83]$. Stress response required GR to increase the AMPA/NMDA ratio at VTA synapses, resulting in enhanced activation of glutamatergic synapses measured $24 \mathrm{~h}$ later [44]. The correct combination of glucocorticoid and BDNF signaling could delineate resiliency from vulnerability and be mediated through
BDNF-dependent GR phosphorylation. If true, then controlling stress exposure could provide vulnerable individuals with the coping skills to ameliorate a variety of phobia and post-traumatic memories [84].

\section{Conclusion}

Proper maintenance of the balance between the corticolimbic and mesolimbic neural networks ensures behavioral choices that are commensurate with the costs and benefits of contextual demands [85]. Integration of positive and negative events over time can induce mood fluctuations. For example, lack of motivation and inflexible maladaptive responses result when prefrontal BDNFTrkB signaling is compromised and GR-mediated responses are desensitized. On the contrary, sensitization to rewarding or aversive conditioning result when mesolimbic BDNF-TrkB signaling is upregulated and GR-mediated responses are bolstered. Desynchronization of BDNF-TrkB and glucocorticoid-GR signaling pathways, in multiple neural networks, through alteration in the GR phosphorylation "code," could explain how decisions are influenced and maladapted in stress-induced mood disorders. More studies are needed to characterize the relative contribution of the distinct neural circuits controlling risk/reward-seeking actions, their connectivity, their neuromodulators (e.g., oxytocin, vasopressin, catecholamine), and their interaction with genetic and environmental factors.

\section{Acknowledgements}

We thank the Fondation pour la Recherche Médicale (F.J., A.B.) and the National Institute of Health (M.J.G., M.V.C., F.J.).

\section{Disclosure Statement}

The authors declare no conflicts of interest.

\section{References}

1 de Kloet ER, Joëls M, Holsboer F. Stress and the brain: from adaptation to disease. Nat Rev Neurosci. 2005 Jun;6(6):463-75.

2 Joëls M, Pu Z, Wiegert O, Oitzl MS, Krugers HJ. Learning under stress: how does it work? Trends Cogn Sci. 2006 Apr;10(4):152-8.

3 Ernst M, Pine DS, Hardin M. Triadic model of the neurobiology of motivated behavior in adolescence. Psychol Med. 2006 Mar;36(3): 299-312.
4 Volman SF, Lammel S, Margolis EB, Kim Y, Richard JM, Roitman MF, et al. New insights into the specificity and plasticity of reward and aversion encoding in the mesolimbic system. J Neurosci. 2013 Nov;33(45):17569-76.

5 Hollon NG, Burgeno LM, Phillips PE. Stress effects on the neural substrates of motivated behavior. Nat Neurosci. 2015 Oct;18(10): 1405-12. 
6 Chattarji S, Tomar A, Suvrathan A, Ghosh S, Rahman MM. Neighborhood matters: divergent patterns of stress-induced plasticity across the brain. Nat Neurosci. 2015 Oct; 18(10):1364-75.

7 McEwen BS, Bowles NP, Gray JD, Hill MN, Hunter RG, Karatsoreos IN, et al. Mechanisms of stress in the brain. Nat Neurosci. 2015 Oct; 18(10):1353-63.

8 Rygula R, Noworyta-Sokolowska K, Drozd R, Kozub A. Using rodents to model abnormal sensitivity to feedback in depression. Neurosci Biobehav Rev. 2018 Dec;95:336-46.

9 Waelti P, Dickinson A, Schultz W. Dopamine responses comply with basic assumptions of formal learning theory. Nature. 2001 Jul; 412(6842):43-8.

10 Russo SJ, Nestler EJ. The brain reward circuitry in mood disorders. Nat Rev Neurosci. 2013 Sep;14(9):609-25.

11 Jensen J, Smith AJ, Willeit M, Crawley AP, Mikulis DJ, Vitcu I, et al. Separate brain regions code for salience vs. valence during reward prediction in humans. Hum Brain Mapp. 2007 Apr;28(4):294-302.

12 Rothwell PE. Autism spectrum disorders and drug addiction: common pathways, common molecules, distinct disorders? Front Neurosci. 2016 Feb; 10:20.

13 Morita K, Kawaguchi Y. Computing rewardprediction error: an integrated account of cortical timing and basal-ganglia pathways for appetitive and aversive learning. Eur J Neurosci. 2015 Aug;42(4):2003-21.

14 Peters A, McEwen BS, Friston K. Uncertainty and stress: why it causes diseases and how it is mastered by the brain. Prog Neurobiol. 2017 Sep;156:164-88.

15 Berridge CW, Waterhouse BD. The locus coeruleus-noradrenergic system: modulation of behavioral state and state-dependent cognitive processes. Brain Res Brain Res Rev. 2003 Apr;42(1):33-84.

16 Hall BS, Moda RN, Liston C. Glucocorticoid mechanisms of functional connectivity changes in stress-related neuropsychiatric disorders. Neurobiol Stress. 2015 Jan;1:17483.

17 Schwabe L, Joëls M, Roozendaal B, Wolf OT, Oitzl MS. Stress effects on memory: an update and integration. Neurosci Biobehav Rev. 2012 Aug;36(7):1740-9.

18 Aston-Jones G, Cohen JD. An integrative theory of locus coeruleus-norepinephrine function: adaptive gain and optimal performance. Annu Rev Neurosci. 2005;28(1):403-50.

19 Jeanneteau F, Chao MV. Neurotrophins and synaptogenesis. In: Rakic P, Rubenstein J, editors. Comprehensive developmental neuroscience: cellular migration and formation of neuronal connections. 2nd ed. Amsterdam: Elsevier; 2013. p. 639-58.

20 Jeanneteau F, Chao MV. Are BDNF and glucocorticoid activities calibrated? Neuroscience. 2013 Jun;239:173-95.
21 Duman RS, Heninger GR, Nestler EJ. A molecular and cellular theory of depression. Arch Gen Psychiatry. 1997 Jul;54(7):597-606

22 Duman RS, Monteggia LM. A neurotrophic model for stress-related mood disorders. Biol Psychiatry. 2006 Jun;59(12):1116-27.

23 Wook Koo J, Labonté B, Engmann O, Calipari ES, Juarez B, Lorsch Z, et al. Essential Role of Mesolimbic Brain-Derived Neurotrophic Factor in Chronic Social Stress-Induced Depressive Behaviors. Biol Psychiatry. 2016 Sep;80(6):469-78.

24 Tsankova N, Renthal W, Kumar A, Nestler EJ. Epigenetic regulation in psychiatric disorders. Nat Rev Neurosci. 2007 May;8(5):35567.

25 Shadrina M, Bondarenko EA, Slominsky PA. Genetics Factors in Major Depression Disease. Front Psychiatry. 2018 Jul;9:334

26 Numata S, Ishii K, Tajima A, Iga J, Kinoshita $\mathrm{M}$, Watanabe S, et al. Blood diagnostic biomarkers for major depressive disorder using multiplex DNA methylation profiles: discovery and validation. Epigenetics. 2015;10(2): $135-41$.

27 Lakshminarasimhan H, Chattarji S. Stress leads to contrasting effects on the levels of brain derived neurotrophic factor in the hippocampus and amygdala. PLoS One. 2012; 7(1):e30481.

28 Barfield ET, Gourley SL. Adolescent Corticosterone and TrkB Pharmaco-Manipulations Sex-Dependently Impact Instrumental Reversal Learning Later in Life. Front Behav Neurosci. 2017 Dec;11:237.

29 Barfield ET, Gerber KJ, Zimmermann KS, Ressler KJ, Parsons RG, Gourley SL. Regulation of actions and habits by ventral hippocampal trkB and adolescent corticosteroid exposure. PLoS Biol.2017 Nov;15(11):e2003000.

30 Autry AE, Monteggia LM. Brain-derived neurotrophic factor and neuropsychiatric disorders. Pharmacol Rev. 2012 Apr;64(2):238-58.

31 Blugeot A, Rivat C, Bouvier E, Molet J, Mouchard A, Zeau B, et al. Vulnerability to depression: from brain neuroplasticity to identification of biomarkers. J Neurosci. 2011 Sep;31(36):12889-99.

32 Berton O, McClung CA, Dileone RJ, Krishnan V, Renthal W, Russo SJ, et al. Essential role of BDNF in the mesolimbic dopamine pathway in social defeat stress. Science. 2006 Feb;311(5762):864-8.

33 Choi DC, Gourley SL, Ressler KJ. Prelimbic BDNF and TrkB signaling regulates consolidation of both appetitive and aversive emotional learning. Transl Psychiatry. 2012 Dec; 2(12):e205.

34 Chou D, Huang CC, Hsu KS. Brain-derived neurotrophic factor in the amygdala mediates susceptibility to fear conditioning. Exp Neurol. 2014 May;255:19-29.

35 Rattiner LM, Davis M, French CT, Ressler KJ. Brain-derived neurotrophic factor and tyrosine kinase receptor B involvement in amygdala-dependent fear conditioning. J Neurosci. 2004 May;24(20):4796-806.
36 Banasr M, Dwyer JM, Duman RS. Cell atrophy and loss in depression: reversal by antidepressant treatment. Curr Opin Cell Biol. 2011 Dec;23(6):730-7.

37 Taliaz D, Loya A, Gersner R, Haramati S, Chen A, Zangen A. Resilience to chronic stress is mediated by hippocampal brain-derived neurotrophic factor. J Neurosci. 2011 Mar;31(12):4475-83.

38 Pitts EG, Li DC, Gourley SL. Bidirectional coordination of actions and habits by TrkB in mice. Sci Rep. 2018 Mar;8(1):4495.

39 Pierce RC, Bari AA. The role of neurotrophic factors in psychostimulant-induced behavioral and neuronal plasticity. Rev Neurosci. 2001;12(2):95-110

40 Poo MM. Neurotrophins as synaptic modulators. Nat Rev Neurosci. 2001 Jan;2(1):24-32.

41 Lobo MK, Covington HE 3rd, Chaudhury D, Friedman AK, Sun H, Damez-Werno D, et al. Cell type-specific loss of BDNF signaling mimics optogenetic control of cocaine reward. Science. 2010 Oct;330(6002):385-90.

42 Graham DL, Krishnan V, Larson EB, Graham A, Edwards S, Bachtell RK, et al. Tropomyosinrelated kinase B in the mesolimbic dopamine system: region-specific effects on cocaine reward. Biol Psychiatry. 2009 Apr;65(8):696-701.

43 Walsh JJ, Friedman AK, Sun H, Heller EA, Ku SM, Juarez B, et al. Stress and CRF gate neural activation of BDNF in the mesolimbic reward pathway. Nat Neurosci. 2014 Jan;17(1):27-9.

44 Saal D, Dong Y, Bonci A, Malenka RC. Drugs of abuse and stress trigger a common synaptic adaptation in dopamine neurons. Neuron. 2003 Feb;37(4):577-82.

45 Finsterwald C, Alberini CM. Stress and glucocorticoid receptor-dependent mechanisms in long-term memory: from adaptive responses to psychopathologies. Neurobiol Learn Mem. 2014 Jul;112:17-29.

46 Barik J, Marti F, Morel C, Fernandez SP, Lanteri C, Godeheu G, et al. Chronic stress triggers social aversion via glucocorticoid receptor in dopaminoceptive neurons. Science. 2013 Jan;339(6117):332-5.

47 Deroche-Gamonet V, Sillaber I, Aouizerate B, Izawa R, Jaber M, Ghozland S, et al. The glucocorticoid receptor as a potential target to reduce cocaine abuse. J Neurosci. 2003 Jun; 23(11):4785-90.

48 Reul JM. Making memories of stressful events: a journey along epigenetic, gene transcription, and signaling pathways. Front Psychiatry. 2014 Jan;5:5.

49 Caudal D, Jay TM, Godsil BP. Behavioral stress induces regionally-distinct shifts of brain mineralocorticoid and glucocorticoid receptor levels. Front Behav Neurosci. 2014 Jan;8:19.

50 Watkeys OJ, Kremerskothen K, Quidé Y, Fullerton JM, Green MJ. Glucocorticoid receptor gene (NR3C1) DNA methylation in association with trauma, psychopathology, transcript expression, or genotypic variation: A systematic review. Neurosci Biobehav Rev. 2018 Dec;95:85-122.
Complementary Roles of Glucocorticoids and BDNF in the Mesocorticolimbic System
Neuroendocrinology 2019;109:277-284 
51 Azogu I, Plamondon H. Blockade of TrkB receptors in the nucleus accumbens prior to heterotypic stress alters corticotropin-releasing hormone $(\mathrm{CRH})$, vesicular glutamate transporter 2 (vGluT2) and glucocorticoid receptor (GR) within the mesolimbic pathway. Horm Behav. 2017 Apr;90:98-112.

52 McGowan PO, Sasaki A, D’Alessio AC, Dymov S, Labonté B, Szyf M, et al. Epigenetic regulation of the glucocorticoid receptor in human brain associates with childhood abuse. Nat Neurosci. 2009 Mar;12(3):342-8.

53 Suderman M, McGowan PO, Sasaki A, Huang TC, Hallett MT, Meaney MJ, et al. Conserved epigenetic sensitivity to early life experience in the rat and human hippocampus. Proc Natl Acad Sci USA. 2012 Oct;109 Suppl 2:1726672.

54 Alt SR, Turner JD, Klok MD, Meijer OC, Lakke EA, Derijk RH, et al. Differential expression of glucocorticoid receptor transcripts in major depressive disorder is not epigenetically programmed. Psychoneuroendocrinology. 2010 May;35(4):544-56.

55 Lee MS, Kim YH, Park WS, Park OK, Kwon $\mathrm{SH}$, Hong KS, et al. Temporal variability of glucocorticoid receptor activity is functionally important for the therapeutic action of fluoxetine in the hippocampus. Mol Psychiatry. 2016 Feb;21(2):252-60.

56 Deroche V, Marinelli M, Maccari S, Le Moal M, Simon H, Piazza PV. Stress-induced sensitization and glucocorticoids. I. Sensitization of dopamine-dependent locomotor effects of amphetamine and morphine depends on stress-induced corticosterone secretion. J Neurosci. 1995 Nov; 15(11):7181-8.

57 Leistner C, Menke A. How to measure glucocorticoid receptor's sensitivity in patients with stress-related psychiatric disorders. Psychoneuroendocrinology. 2018 May;91:23560.

58 Anacker C, Zunszain PA, Carvalho LA, Pariante CM. The glucocorticoid receptor: pivot of depression and of antidepressant treatment? Psychoneuroendocrinology. 2011 Apr; 36(3):415-25.

59 Holsboer F, Ising M. Stress hormone regulation: biological role and translation into therapy. Annu Rev Psychol. 2010;61:81-109.

60 Castrén E, Antila H. Neuronal plasticity and neurotrophic factors in drug responses. Mol Psychiatry. 2017 Aug;22(8):1085-95.

61 Arango-Lievano M, Lambert WM, Bath KG, Garabedian MJ, Chao MV, Jeanneteau F. Neurotrophic-priming of glucocorticoid receptor signaling is essential for neuronal plasticity to stress and antidepressant treatment Proc Natl Acad Sci USA. 2015 Dec;112(51): 15737-42.
62 Lambert WM, Xu CF, Neubert TA, Chao MV, Garabedian MJ, Jeanneteau F. Brain-derived neurotrophic factor signaling rewrites the glucocorticoid transcriptome via glucocorticoid receptor phosphorylation. Mol Cell Biol. 2013 Sep;33(18):3700-14.

63 Arango-Lievano M, Jeanneteau F. Timing and crosstalk of glucocorticoid signaling with cytokines, neurotransmitters and growth factors. Pharmacol Res. 2016;113(Pt A):1-17.

64 Cattaneo A, Cattane N, Begni V, Pariante $\mathrm{CM}$, Riva MA. The human BDNF gene: peripheral gene expression and protein levels as biomarkers for psychiatric disorders. Transl Psychiatry. 2016 Nov;6(11):e958.

65 Chen DY, Bambah-Mukku D, Pollonini G, Alberini CM. Glucocorticoid receptors recruit the CaMKIIa-BDNF-CREB pathways to mediate memory consolidation. Nat Neurosci. 2012 Dec;15(12):1707-14.

66 Gourley SL, Swanson AM, Jacobs AM, Howell JL, Mo M, Dileone RJ, et al. Action control is mediated by prefrontal BDNF and glucocorticoid receptor binding. Proc Natl Acad Sci USA. 2012 Dec;109(50):20714-9.

67 Revest JM, Le Roux A, Roullot-Lacarriere V, Kaouane N, Vallee M, Kasanetz F, et al BDNF-TrkB signaling through Erk1/2 phosphorylation mediates the enhancement of fear memory induced by glucocorticoids. Mol Psychiatry. 2014 Sep;19(9):1001-9.

68 Arango-Lievano M, Peguet C, Catteau M, Parmentier ML, Wu S, Chao MV, et al. Deletion of Neurotrophin Signaling through the Glucocorticoid Receptor Pathway Causes Tau Neuropathology. Sci Rep. 2016 Nov;6(1): 37231.

69 Jeanneteau F, Barrère C, Vos M, De Vries CJ, Rouillard C, Levesque D, et al. The stress-induced transcription factor NR4A1 adjusts mitochondrial function and synapse number in prefrontal cortex. J Neurosci. 2018 Feb;38(6): 1335-50.

70 Garabedian MJ, Harris CA, Jeanneteau F. Glucocorticoid receptor action in metabolic and neuronal function. F1000 Res. 2017 Jul;6: 1208.

71 Paugh SW, Bonten EJ, Savic D, Ramsey LB, Thierfelder WE, Gurung P, et al. NALP3 inflammasome upregulation and CASP1 cleavage of the glucocorticoid receptor cause glucocorticoid resistance in leukemia cells. Nat Genet. 2015 Jun;47(6):607-14.

72 Pittenger C, Duman RS. Stress, depression, and neuroplasticity: a convergence of mechanisms. Neuropsychopharmacology. 2008 Jan; 33(1):88-109.

73 Selye H. The stress of life. New York: McGrawHill; 1956.

74 Kessler RC, Demler O, Frank RG, Olfson M, Pincus HA, Walters EE, et al. Prevalence and treatment of mental disorders, 1990 to 2003. N Engl J Med. 2005 Jun;352(24):2515-23.
75 Cohen S, Janicki-Deverts D, Doyle WJ, Miller GE, Frank E, Rabin BS, et al. Chronic stress, glucocorticoid receptor resistance, inflammation, and disease risk. Proc Natl Acad Sci USA. 2012 Apr;109(16):5995-9.

76 Egan MF, Kojima M, Callicott JH, Goldberg TE, Kolachana BS, Bertolino A, et al. The BDNF val66met polymorphism affects activity-dependent secretion of BDNF and human memory and hippocampal function. Cell. 2003 Jan;112(2):257-69.

$77 \mathrm{Yu} \mathrm{H}$, Wang DD, Wang Y, Liu T, Lee FS, Chen ZY. Variant brain-derived neurotrophic factor Val66Met polymorphism alters vulnerability to stress and response to antidepressants. J Neurosci. 2012 Mar;32(12):4092-101.

78 Shalev I, Lerer E, Israel S, Uzefovsky F, Gritsenko I, Mankuta D, et al. BDNF Val66Met polymorphism is associated with HPA axis reactivity to psychological stress characterized by genotype and gender interactions. Psychoneuroendocrinology. 2009 Apr;34(3): 382-8.

79 Rougé-Pont F, Deroche V, Le Moal M, Piazza $\mathrm{PV}$. Individual differences in stress-induced dopamine release in the nucleus accumbens are influenced by corticosterone. Eur J Neurosci. 1998 Dec; 10(12):3903-7.

80 Piazza PV, Le Moal M. The role of stress in drug self-administration. Trends Pharmacol Sci. 1998 Feb;19(2):67-74.

81 Franklin TB, Saab BJ, Mansuy IM. Neural mechanisms of stress resilience and vulnerability. Neuron. 2012 Sep;75(5):747-61.

82 Russo SJ, Murrough JW, Han MH, Charney DS, Nestler EJ. Neurobiology of resilience. Nat Neurosci. 2012 Nov;15(11):1475-84.

83 Srinivasan S, Shariff M, Bartlett SE. The role of the glucocorticoids in developing resilience to stress and addiction. Front Psychiatry. 2013 Aug; 4:68.

84 Nechvatal JM, Lyons DM. Coping changes the brain. Front Behav Neurosci. 2013 Feb;7: 13.

85 Vinckier F, Rigoux L, Oudiette D, Pessiglione M. Neuro-computational account of how mood fluctuations arise and affect decision making. Nat Commun. 2018 Apr;9(1):1708.

86 Galliher-Beckley AJ, Cidlowski JA. Emerging roles of glucocorticoid receptor phosphorylation in modulating glucocorticoid hormone action in health and disease. IUBMB Life. 2009 Oct;61(10):979-86.

87 Wang Z, Frederick J, Garabedian MJ. Deciphering the phosphorylation "code" of the glucocorticoid receptor in vivo. J Biol Chem. 2002 Jul;277(29):26573-80.

88 Galliher-Beckley AJ, Williams JG, Cidlowski JA. Ligand-independent phosphorylation of the glucocorticoid receptor integrates cellular stress pathways with nuclear receptor signaling. Mol Cell Biol. 2011 Dec;31(23):4663-75. 